\title{
Computer vision syndrome
}

\begin{abstract}
Aim: To investigate the computer related eye problems (as special near work).

Material and methods: This is field-based, descriptive, cross sectional, case control study. We selected about 100 computer users according the following inclusion criteria: Continuous use of the computer for at least 1 year. Using of the computer every day for at least 4 hours (except official holidays). Exclusion criteria are: Anyone having P.H of the symptoms or signs of CVS before computer using and anyone with ocular disease (i.e. glaucoma, conjunctivitis). We select another group from the same area and of the same range of age (100 subjects) as control group. A complete medical examination was performed.
\end{abstract}

Results: The study showed that symptoms and signs in the computer users are greatly higher than in the control group, $(\mathrm{p}=0.001)$. The odds ratio for the most of the symptoms and signs were also high. The study showed that there are relation between the symptoms and signs and the time (hours) per day and duration per year of exposure to the computer.

Conclusion: Users of the computers are subject to visual problems. These effects tend to be significant as the time of the exposure per day and the duration per year increases.
Volume 4 Issue 3 - 2016

\section{Atif Mussa}

Najran University Hospital, Saudi Arabia

Correspondence: Atif Mussa, Najran University, Najran university hospital, Najran Saudi Arabia, Tel 0096650223946I, Email attiformerl@hotmail.com

Received: May 04, 2016 | Published: May 25, 2016

Keywords: computer vision syndrome, precorneal tears film, near response and accommodation

Abbreviations: VDT, video display terminal; CVS, computer vision syndrome; RPA, resting point of accommodation

\section{Introduction}

During the last decades, the increased use of computers in the workplace has brought about the development of a number of health concerns. Many individuals who work at a computer or video display terminal (VDT) report a high level of job-related complaints and symptoms. The American Optometric Association defined these S\&S as CVS.

\section{Functional anatomy of the eye}

The eyes are protected from injury and excessive light by eye lids and their closure. The eye lids assist in the distribution of tears over the anterior surface of the eye ball. ${ }^{1-3}$ The principle optical element of the eye is the anterior surface of the cornea, which is covered by a thin tear film. The eyelid functions to maintain the integrity of the corneal surface and its thin layer of tear by blinking process. ${ }^{3,4}$ Loss of this blinking action will result in an immediate degradation in the health of the corneal surface. ${ }^{1-4}$ Spontaneous blinking is the blinking occurs on regular basis without an apparent external stimulus. The spontaneous blinking rate in human adult is $15 /$ minute, and the duration of each blink varies from $300-400$ msec. $^{4}$

The normal blinking rate is determined by the activity of the blinking centre in the brain and modified by external stimuli..$^{1,3,4}$ The tear film on the surface of the cornea is called precorneal film and it consists of three layers. ${ }^{1-4}$ It is 7-10 micrometer in thickness. The movement of the tear film is from the outer canthus toward the medial canthus along the lacrimal strips or rivers and it is driven by the muscular action of the orbicularis muscle of the eyelid (blinking). ${ }^{1-4}$
When near object is focused, three events occur simultaneously, convergence, accommodation and pupillary constriction (miosis)..$^{1,3,4}$ Accommodation is the required increase in dioptric power of the system when the object is closer than infinity, to focusing the image of this object on the retina clear. ${ }^{1,3,4}$ Amplitude of accommodation is the difference in refracting power of the eye in the two states of complete relaxation and maximal accommodation. ${ }^{1,4}$ Under normal circumstances most near work is done at a distance of 25 to $40 \mathrm{~cm}$. If the non accommodating eye is emmetropic (i.e. retina conjugate with infinity) or if any ametropia is corrected by spectacle or contact lenses, 2.5 to 4 diopters of accommodation is required to clearly see objects at this distance. ${ }^{4}$

\section{The computer}

The term monitor is usually refers to the entire box, whereas display screen can mean just the screen. In addition, the term monitor often implies graphics capabilities. ${ }^{5}$ There are many ways to classify monitors. Color monitors can display anywhere from 16 to over 1 million different colors. ${ }^{5,6}$ Important aspect of the monitor is its screen size which is measured in diagonal inches. ${ }^{5}$ Other factors that determine a monitor's quality include Bandwidth, Refresh rate, Interlaced or noninterlaced, dot pitch, and Convergence. Screen resolution signifies the number of dots (pixels) on the entire screen. ${ }^{5}$

Graphics monitors display pictures by dividing the display screen into thousands (or millions) of pixels, arranged in rows and columns. The pixels are so close together that they appear connected. The quality of a display system largely depends on its resolution, how many pixels it can display, and how many bits are used to represent each pixel. True Color systems use 24 bits per pixel, allowing them to display more than 16 million different colors. ${ }^{5}$ 


\section{Computer vision syndrome (CVS)}

The American optometrist association defines CVS as: It is the complex of the eye and vision problem related to near work which are experience during or related to computer use. CVS characterized by visual symptoms which result from interaction with computer display or its environment. ${ }^{7}$ In most cases, symptoms occur because the visual demand of the task exceeds the visual abilities of the individual to comfortably perform the task. ${ }^{7}$ The symptoms of the CSV are headache, blurring vision, burning sensation, eye redness, and pain, lacrimation, focusing problem, neck and shoulder pain. ${ }^{7-9}$ If the individual spend more than two hours each day in front of a computer screen, he likely to experiences some symptoms of computer vision syndrome CVS is caused by the eyes reacting differently to characters on the screen than they do to printed characters.

The eyes respond well to most printed material, which is characterized by its dense black characters with well-defined edges which contrast markedly from their light background. Healthy eyes can easily maintain focus on the printed page. ${ }^{9}$ Characters on a computer screen, however, don't have this contrast, or well-defined edges. These characters are brightest at their centers and diminish in intensity toward their edges. The eyes are unable to maintain focus and remain on plane with these images. They instead drift out to a point called the resting point of accommodation (RPA) and then refocus on the screen. This continuous flexing of the eyes focusing muscles creates fatigue and the burning, tired eyes feeling. ${ }^{8,9}$ The principal factors affecting the ability to see well are the glare, the amount of light and the luminance (brightness), the distance between the eye and the screen and document, the readability of the screen and document and the angle made by the visual axis with the screen..$^{7-9}$

\section{Material and methods}

This is field-based, descriptive, cross sectional, case control study done in Alawkaf market in Khartoum in January 2005 to January 2006. We selected about 50 computer users according the following inclusion criteria: Continuous use of the computer for at least 1 year. Using of the computer every day for at least 4 hours (except official holidays). Exclusion criteria are: Anyone having P.H of the symptoms or signs of CVS before computer using and anyone with ocular disease (i.e. glaucoma, conjunctivitis). We select another group from the same area and of the same range of age ( 55 subjects) as control group. Data was collected by filling questionnaire papers about age, sex, blurring vision, burning sensation, ocular pain, itching, foreign body sensation, photophobia, any tearing problem, discharge, and diminution of vision. Then we did complete eye examination. Statistical analysis was done by SPSS system and weighting the data with the age (ageadjusted) for the Pearson chi-square tests (p-value) while the odds and the odds ratio were calculated manually.

\section{Results}

General characteristic of the groups: The age of the study group ranged 20-35 years with a mean \pm standard deviation of $26.7 \pm 3.69$. The mean \pm standard deviation of the control group was $27.54 \pm 5.479$. The period of using the computer per day was 6-14hours with a mean \pm standard deviation $10.34 \pm 2.246$ while it was negligible in the control group. The duration of the using computer was 1-14 years with a mean \pm standard deviation of $4.918 \pm 2.928$ while it was $4.5455 \pm 2.0259$ in the control group. The distance between the tested group and the computer screen was $45-78 \mathrm{~cm}$ with a mean \pm standard deviation of $57.4 \pm 7.131$ while for the control group it was $45-70 \mathrm{~cm}$ with a mean \pm standard deviation of $56.309 \pm 6.757$.

\section{Discussion}

As far as we know, no study has been undertaken to explore the eye problems-related computer using with respect to symptoms and signs in Sudan. The study showed that the eye problems in the computer users are greatly higher than in the non-computer group ( $\mathrm{p} 0.000)$. The study also showed that there are relation between the symptoms and signs and the time (hours) per day and duration per year of exposure to the computer.

From this study we found $44 \%$ of the computer user group had headache compared to (18\%) in the control group (p0.004098) which is significant and means that the headache in the computer user group is somehow related to the computer use. The same observation was proved out by Salibell et al., ${ }^{10}$ in their study $42 \%$. The odds ratio for the headache was 3.5357 which further indicate that the headache in the computer users is genuine to the computer use. The same observations were found in relation to symptoms of blurring of vision, burning sensation of the eye, ocular pain, eye redness and tearing problems. The percent of subjects who had blurring of vision in the computer user group was $62 \%$ compared to $12.7 \%$ in the control group P 1.54319E-07 which is highly significant and indicate that blurring of vision in the computer user group is genuine to the computer use. The same observation was proved out by Salibell et al in their study $65 \%{ }^{10}$ The odd ratio for the blurred vision is 11.187 which further indicate that blurred vision in the computer users group is related to the computer use.

The subjects who had burning sensation of the eye were $46 \%$ in the computer users group while they are only $16.3 \%$ in the control group (P 0.0009843) and it is significant and means that the burning sensation of the eye is somehow related to the computer use. The result is lower than that found by Salibell et al., ${ }^{10}$ in their study (65\%). The odds ratio for the burning sensation is 4.3539 which indicate that the burning sensation in the computer users group is related to the computer using. The eye redness occurred in $54 \%$ in the computer users group versus $20 \%$ in the control group (P0.0002936) and it is also significant. The odds ratio is 4.6956 which further prove that the eye redness in the computer user group is related to computer use.

The ocular pain occurred in $1734 \%$ in the computer users group compared to $10.9 \%$ in the control group ( $\mathrm{p} 0.004278)$ and it is again significant. This result is differing (lower) from the results of the study done by Iwakiri et al., ${ }^{11}$ (72\%). The odd ratio is 4.2071 which indicate that the ocular pain the computer user group is genuine to the computer use. The subjects who had tear problems are $40 \%$ in the computer users group while they are $9.09 \%$ in the control group (P0.000204076) and it is significant. The odds ratio is 6.6667 which indicate that the tears problem in the computer user group is related to the computer use.

The study revealed that the symptoms and the signs are increased with increasing the time of exposure to the computer per day. The results are similar to the results of the study done by Knave et al., ${ }^{12}$ (Tables 1-4). Also Shimai et al., ${ }^{13}$ and Sugita et al., ${ }^{14}$ had similar results. The study also revealed that the signs and symptoms are increased with increasing the duration of exposure to the computer per year. The result is similar to the results of the study done by Trayers et al., ${ }^{15}$ and Shimai et al. ${ }^{13}$ 
Table I Time of exposure per day (hrs) and Duration of exposure (years) for all groups

\begin{tabular}{lllll}
\hline & Age & $\begin{array}{l}\text { Time of exposure per Day } \\
\text { (hrs) }\end{array}$ & $\begin{array}{l}\text { Duration of exposure } \\
\text { (years) }\end{array}$ & $\begin{array}{l}\text { Distance bet sub \& C } \\
(\mathbf{c m})\end{array}$ \\
\hline $\begin{array}{l}\text { Tested group mean } \pm \text { STD } \\
\text { Control group mean } \pm\end{array}$ & $\begin{array}{l}26.7 \pm 3.7 \\
27.54 \pm\end{array}$ & $10.34 \pm 2.25$ & $4.92 \pm 2.93$ & $57.4 \pm 7.13$ \\
STD & 5.48 & $1.05 \pm 0.66$ & $4.55 \pm 2.03$ & $56.3 \pm 6.76$ \\
\hline
\end{tabular}

Table 2 Odds ratio and p-value for symptoms and signs in tested and control groups

\begin{tabular}{lllll}
\hline & \% of Tested Group & \% of control group & Odds ratio & P-value \\
\hline Headache & 44 & 18 & 3.535 & 0.004 \\
Burning Sense & 46 & 16.3 & 4.354 & 0 \\
Blurring Vision & 62 & 12.7 & 1 I.I87 & $1.54 \mathrm{E}-07$ \\
Tear Problems & 40 & 9.1 & 6.667 & 0 \\
Ocular Pain & 34 & 10.9 & 4.207 & 0.004 \\
Redness & 54 & 20 & 4.695 & 0
\end{tabular}

Table 3 Symptoms and signs per subject according to time per day (hrs)

\begin{tabular}{llll}
\hline Duration (hrs) & Total of S\&S & Number of Subject & S\&S per Subject \\
\hline 6 & 4 & 3 & 1.333 \\
7 & 6 & 3 & 2 \\
8 & 21 & 7 & 3 \\
9 & 12 & 4 & 3 \\
10 & 17 & 8 & 2.125 \\
11 & 22 & 5 & 4.4 \\
12 & 30 & 12 & 2.5 \\
13 & 14 & 5 & 2.8 \\
14 & 14 & 3 & 4.666 \\
Total & 140 & 50 & 2.8 \\
\hline
\end{tabular}

Table 4 Symptoms and signs per subject according to duration (years)

\begin{tabular}{llll}
\hline Duration (years) & Total of S\&S & Number of subject & S\&S per subject \\
\hline I & 7 & 5 & 1.4 \\
2 & 18 & 6 & 3 \\
3 & 24 & 7 & 3.43 \\
4 & 14 & 6 & 2.33 \\
5 & 17 & 5 & 3.4 \\
6 & 29 & 10 & 2.9 \\
7 & 7 & 2 & 3.5 \\
8 & 3 & 2 & 1.5 \\
9 & 2 & 1 & 2 \\
10 & 10 & 3 & 3.33 \\
II & 4 & 1 & 4 \\
14 & 4 & 1 & 4 \\
Total & 139 & 49 & 2.84 \\
\hline
\end{tabular}




\section{Conclusion and recommendations}

Computer users have their effects on the eye and vision. These effects tend to increase as the time of the exposure per day and the duration per year increases. The risk of permanent functional damage is not low at long term (more than 6 years) and may there are some sort of permanent effects on the eyes due to the computer use which needs years to appear. These groups of people need special ophthalmological follow up and assessment of regular interval i.e. every 3-6 month. Still these problems need a lot of research to determine whether there are really pathological changes or it is just a matter of physiological changes or physiological eyestrain!

\section{Acknowledgments}

None.

\section{Conflicts of interest}

The author declares there are no conflicts of interest.

\section{References}

1. American Academy of Ophthalmology: fundamental and principle of ophthalmology: Section two, Basic \& Clinical Science Course. 20112012 .

2. American Academy of Ophthalmology: External Disease and Cornea: Section Seven, Basic \& Clinical Science Course. American Academy of Ophthalmology; 2011-2012.

3. Davson, Hugh. Physiology of the eye. 5th edn. MAC Millan Academic and Professional Ltd-London. 1991.

4. William Hart. Adler's physiology of the eye. 9th edn. Mosby year book, USA. 1992.
5. Gibson Research Corporation. Sub-pixel font rendering work.

6. http://www.webopedia.com/TERM/m/monitor.html

7. American Optometric Association. Guide to the clinical aspect of computer vision syndrome. St. Louis: American Optometric Association. 1995:1

8. Sheedy JE. Vision problems at video display terminals: a survey of optometrist. J Am Optom Assoc. 1992;63(10):687-692.

9. Campbell FW, Durden K. The visual display terminal issue: A consideration of its physiological, psychological and clinical background. Ophthal Physiol Opt. 1983;3(2):175-192.

10. Salibello C, Nilsen E. Is there a typical DVT patient? A demographic analysis. J Am Optom Assoc. 1995;66(8):479-483.

11. Iwakiri K, Mori I, Sotoyama M, et al. Survey on visual and musculoskeletal symptoms in VDT workers. Sangyo Eisi Igaku Zasshi. 2004;46(6):201212.

12. Knave BG, Wibom RI, Voss M, et al. Work with VDT among office employee. Subjective symptoms and discomfort. Scand $J$ Work EnviroHealth. 1985;11(6):457-466.

13. Shimai S, Iwasaki S, Takashi M, et al. Survey on subjective symptoms in VDT workers: compliant rate and year of service. Sangyo Igaku. 1986;28(2):87-95.

14. Sugita M, Minowa $\mathrm{H}$, Ishii M, et al. factors affecting subjective symptoms of VDT workers. Sangyo Igaku. 1986;28(6):409-419.

15. Travers PH, Stanton BA. Office worker and VDT: physical, psychological and ergonomic factors. AAOHN J. 2002;50(11):489-493. 